\title{
High Efficient Permanent Magnet Synchronous Motor Design, Electromagnetic and Noise- Vibration Analyzes
}

\author{
A. ŞAHIN, Y. ÖNER
}

\begin{abstract}
In this study, it was aimed to carry out the design, electromagnetic analysis and noise-vibration analysis of a 3 phase, high efficient surface mounted permanent magnet motor with power level of $7.5 \mathrm{~kW}$ and $1500 \mathrm{rpm}$ speed. Using basic analytical formulas initial design geometry of motor was obtained. This first design geometry was investigated in detail by electromagnetic analyzes. In these electromagnetic analyzes, cogging torque, torque ripple, losses and efficiency parameters have been investigated. Then, modal and harmonic analyzes were carried out in order to interpret the effect of radial harmonic forces, obtained from electromagnetic analyzes, on the stator teeth on the noise and vibration parameters of the motor. According to analysis result of initial designed motor, it was aimed to reduce cogging torque, torque ripple, efficiency, noise and vibration parameters. It is thought that the improvement studies to be perform in the cogging torque will also have a positive effect on the torque ripple and vibration on the motor. By optimizing studies performed magnet and lamination geometry, new motor geometry has been obtained. Electromagnetic, modal, harmonic analyzes were made this new motor geometry. Analysis results of the new design and the first design were studied comparatively.
\end{abstract}

Index Terms-Cogging Torque, efficiency, noise, permanent magnet motor, vibration.

\section{INTRODUCTION}

$\mathrm{P}$ ermanent magnet synchronous are widely used in industrial application, electrical appliances and electrical vehicle applications. In addition to the widespread use of permanent magnet synchronous motors, with the increasing importance of energy efficiency throughout the world, many

ATAKAN SSAHIN, is with Department of Electrical Engineering University of Yıldız Technical University, Gamak Makina Sanayi A.Ş, Istanbul, Turkey,(e-mail: atknshn1@gmail.com).

iD https://orcid.org/0000-0001-5870-0147

YASEMIN ÖNER, with Department of Electrical Engineering University of Y1ldız Technical University, Istanbul, Turkey,(e-mail: yoner@yildiz.edu.tr).

ID https://orcid.org/0000-0002-5310-6875

Manuscript received November 30, 2020; accepted January 15, 2021. DOI: $\underline{10.17694 / \text { bajece. } 851043}$ studies are carried out on these motors in academia and industry. These studies considering that the pulling force applied by the magnet in the rotor of these motors to the stator teeth causes the cogging torque. At the same time, there are many studies on the negative effect of torque ripple on motors and reducing this ripple. One of the most important issues emphasized in the studies is the efficiency of the motors. In permanent magnet synchronous machines, it is quite possible to obtain higher efficiency and power in smaller volumes compared to other traditional electric motors.

With the discovery of magnets such as "' $\mathrm{Nd}-\mathrm{Fe}$ B''(Neodymium Iron Boron) and 'Sm-Co"'(Samarium Cobalt) with high remanence, high energy and high magnetic field intensity values as shown figure 1 that are subjected to demagnetization in early 1980 s, studies on permanent magnet motors gained speed $[1,2]$.

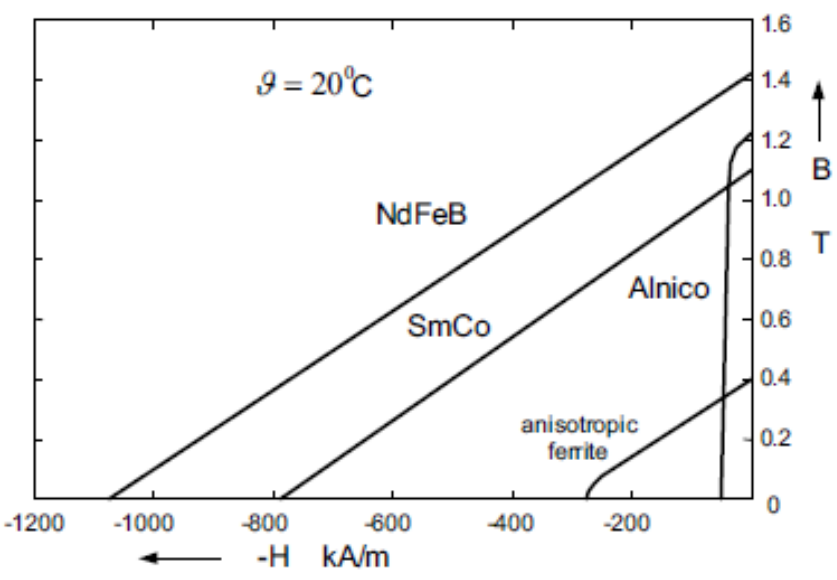

Fig.1. Demagnetization Curves of Different Magnet Materials [2]

These motors, which do not have conductors in their rotor, provide great advantages over other motor types both terms of efficiency and dimension with the use of high energy magnets such as "Nd-Fe-B" and "Sm-Co".

As with other electric motors in permanent magnet synchronous motors, the generation of noise and vibration is a subject that needs to be studied in detail. Noise and vibration in these motors are examined under three main titles as electromagnetic, mechanical and aerodynamic as shown figure2. Especially in the electric vehicles, aviation and servo industry, the generation of noise and vibration have high importance $[3,4,5]$. 
Electromagnetic noise and vibration occurs when radial electromagnetic forces in the air gap effect on the stator teeth. It is not possible to eliminate these forces, but these forces can be minimized. These forces cause the stator stack and the frame to be deformed over time due to the vibration effect $[3,4,5]$.

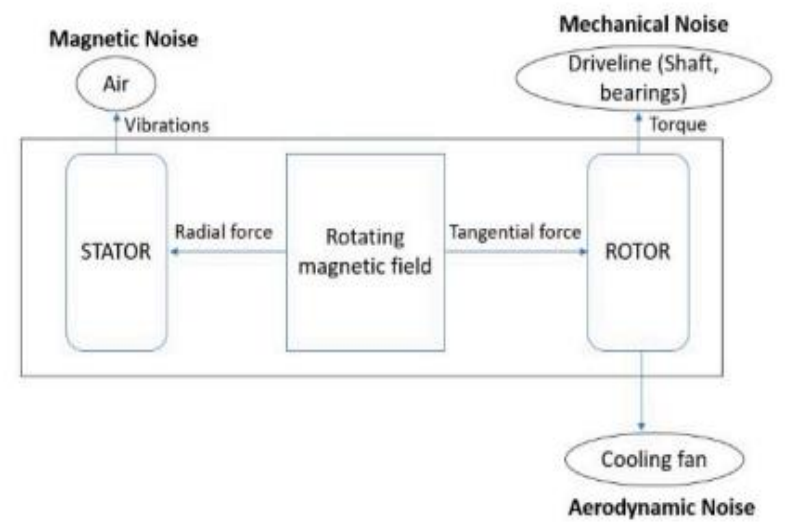

Fig.2. Generation of Noise and Vibration Origins in a Rotating Electrical Machine [5]

\section{DETERMINATION OF DESIGN CRITERIA AND LAMINATION STRUCTURE}

Firstly, the minimum target efficiency value to be obtained in the analysis result was determined as $\% 92,6$ based on IEC 60034-30-1 efficiency standard of the motor, which will be designed at $230 \mathrm{~V}$ phase voltage with IE4 efficiency class and $7.5 \mathrm{~kW}$ power level at $1500 \mathrm{rpm}$ rotational speed. According the diameter of the motor frame maximum stator outer diameter is determined as $218 \mathrm{~mm}$. For 4 pole surface magnet synchronous motor number of stator slots was chosen as 36 and accordingly, it was decided to use a single layer distributed winding type. The surface magnet structure has been determined for design of rotor structure.

TABLE I

DESIGN PARAMETERS

\begin{tabular}{cc}
\hline \hline Parameters & Value \\
\hline \hline Output Power (kW) & 7.5 \\
Speed (rpm) & 1500 \\
Phase Voltage (V) & 230 \\
Phase Current(rms) (A) & 14.85 \\
Target Efficiency (\%) & 92.6 \\
\hline \hline
\end{tabular}

\section{INITIAL DESIGN}

First, the main dimensions of the motor are determined by using basic motor analytical formulas. Then the stator lamination and winding arrangement were determined and rotor magnet dimensions were determined. Lamination geometry was obtained as shown figure 3 and dimensions were shown table II.

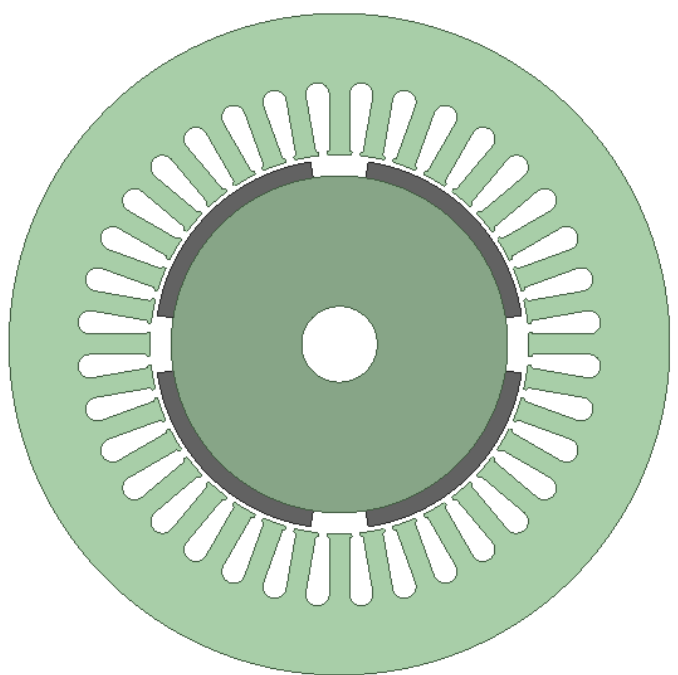

Fig.3. Stator and Rotor Structure

TABLE II

INITIAL DESIGN MOTOR DIMENSIONS

\begin{tabular}{cc}
\hline \hline Parameter & Value \\
\hline \hline Stator Outer Diameter(mm) & 218 \\
Stator Inner Diameter (mm) & 125 \\
Stator-Rotor Stack Length (mm) & 120 \\
Slot Number & 36 \\
Slot Height (mm) & 24 \\
Stator Tooth Width (mm) & 6.6 \\
Airgap (mm) & 1.5 \\
Max. Magnet Thickness (mm) & 5.5 \\
Min. Magnet Thickness (mm) & 5.3 \\
Magnet Width (Electrical Degree) & 144 \\
Magnet Axial Length (mm) & 120 \\
Number of Turn in One Coil & 19 \\
Wire Diameter (mm) & 1.02 \\
Number of Wire & 4 \\
Steel Material & $50 \mathrm{JN} 400$ \\
Magnet Material & $\mathrm{N} 45 \mathrm{M}$ \\
\hline \hline
\end{tabular}

\section{A. Initial Design Electromagnetic Analyzes}

Electromagnetic analyzes were carried out in $2 \mathrm{D}$ with the finite element method using Ansys Maxwell software. In these analyzes made with sinusoidal current supply, moment, output power, flux - flux densities, cogging torque, losses and efficiency parameters are examined. In order to obtain more realistic results in analyzes to be perform, the mesh number was increased, as shown figure 4 , by keeping the size of the mesh element thrown into the air gap and magnets. 


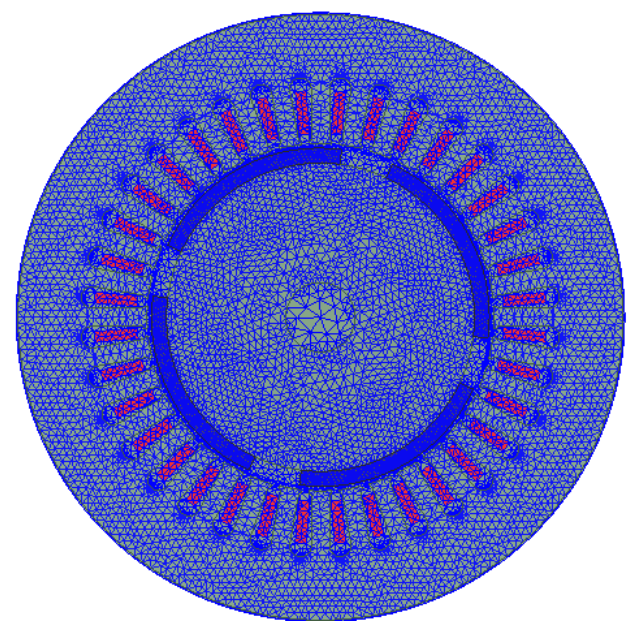

Fig.4. Mesh View

\section{B. Torque Analysis}

To obtain output power level of motor $7.5 \mathrm{~kW}$ at $1500 \mathrm{rpm}$ speed;

$$
T=\frac{p}{\omega}
$$

$47.75 \mathrm{Nm}$ rated torque was obtained using the formula. Where $\mathrm{P}$ is the output power of the motor, $\omega$ is the angular velocity of the motor.



Fig.5. Torque Graph

TABLE III

Torque Values

\begin{tabular}{ccc}
\hline \hline $\begin{array}{c}\text { Maximum } \\
\text { Torque(Nm) }\end{array}$ & $\begin{array}{c}\text { Minimum } \\
\text { Torque(Nm) }\end{array}$ & Torque Ripple (\%) \\
\hline \hline 52.65 & 44.12 & 17.64 \\
\hline \hline
\end{tabular}

When the motor is operating under load at 1500rpm, the difference between maximum torque and minimum torque is clearly observed when the torque value is examined. Accordingly, torque ripple was calculated as $17.64 \%$ from figure 5.

\section{Flux Density Analysis}

It has been observed that the flux densities do not lead the $50 \mathrm{JN} 400$ electrical steel to the saturation point, as seen figure 6 and table IV, when the motor is fed with its nominal current and at nominal output power.

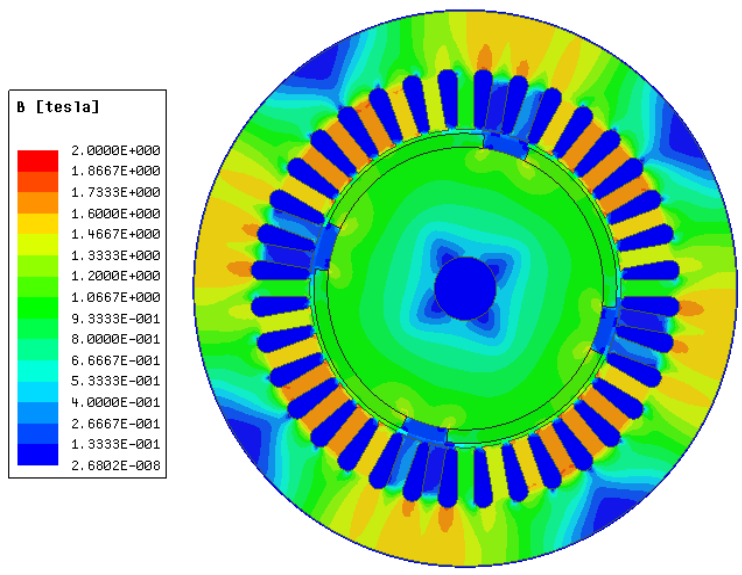

Fig.6. Flux Densities

TABLE IV

Max. Flux Densities

\begin{tabular}{cc}
\hline \hline Parameters & Value (T) \\
\hline \hline Stator Yoke & 1,6 \\
Stator Tooth & 1,73 \\
Air Gap & 1,16 \\
Rotor Yoke & 1,27 \\
\hline \hline
\end{tabular}

\section{Determination of Losses}

After the flux density analysis, the losses of the motor at the nominal power and speed were examined. Core and magnet losses were obtained by analyzing the finite element method. While calculating the copper losses, the stator winding temperature was accepted as $80^{\circ} \mathrm{C}$ in the thermal stability of the motor, and the copper losses were calculated according to the winding resistance at $80^{\circ} \mathrm{C}$.
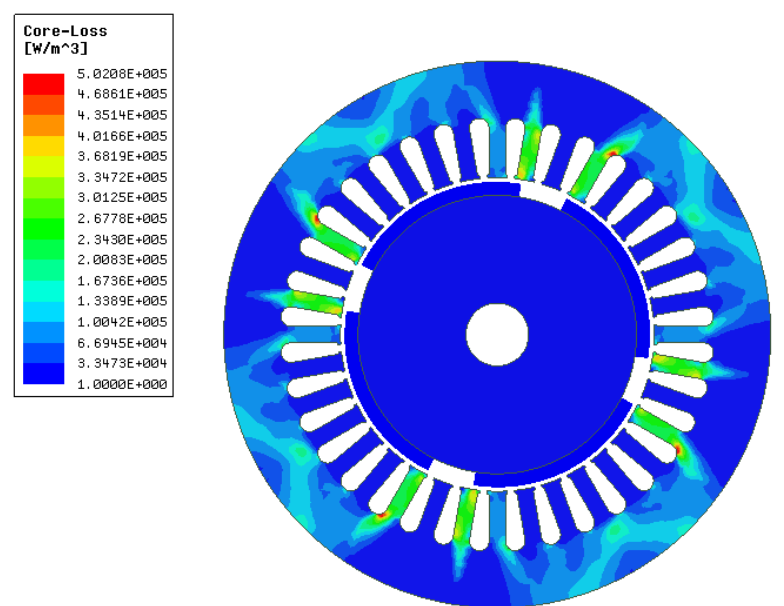

Fig.7. Core Losses 


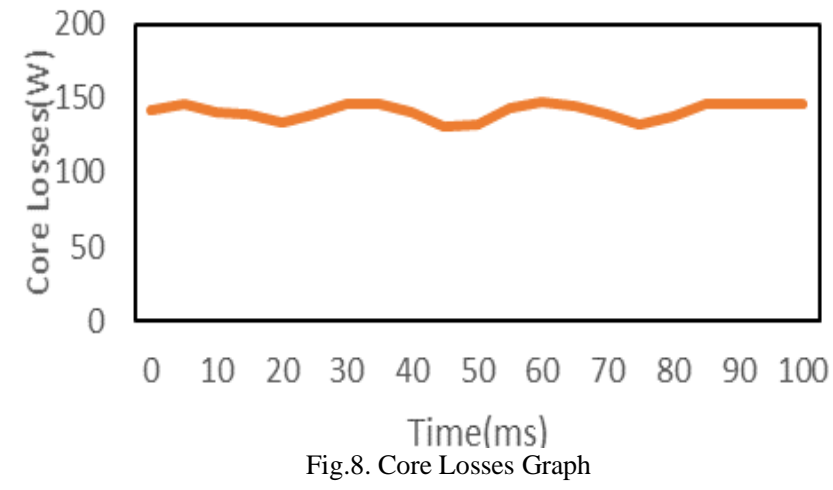

When the iron losses became stable, $140.75 \mathrm{~W}$ was obtained as the average value at figure 8 core losses graph. Efficiency value of motor was obtained summation of losses as seen table V.

TABLE V

Losses and Efficiency

\begin{tabular}{lc}
\hline \hline Losses & Value \\
\hline \hline Copper Losses (W) & 325,7 \\
Core Losses (W) & 140,75 \\
Magnet Losses (W) & 3,4 \\
Friction and Windage Losses(W) & 28 \\
Additional Losses (W) & 51 \\
\hline \hline Total Losses(W) & 548,85 \\
\hline \hline Efficiency (\%) & 93,18 \\
\hline \hline
\end{tabular}

\section{E. Cogging Torque Analysis}

Cogging torque is the interaction between the stator teeth and the magnets when the phases are not supplied with current. Basically the strain felt when turning the shaft of the motor manually is called the cogging torque. Keeping this undesirable torque at the lowest possible value is very important in terms of torque ripple, noise and vibration $[7,8]$.

$$
T_{\text {cogging }}=\frac{1}{2} B_{r} \frac{\mathbb{A}_{m}}{\mu_{0} \mu_{r}} \frac{d \phi_{r}}{d \theta}
$$

Here $\mathrm{Br}$ is the magnet remanence value, $\mu_{0}$ is the magnetic permeability of the air, $\mu_{\mathrm{r}}$ is the relative magnetic permeability of the magnet, $\emptyset_{\mathrm{r}}$ is the flux of the magnet, $1_{\mathrm{m}}$ is magnet thickness[6].

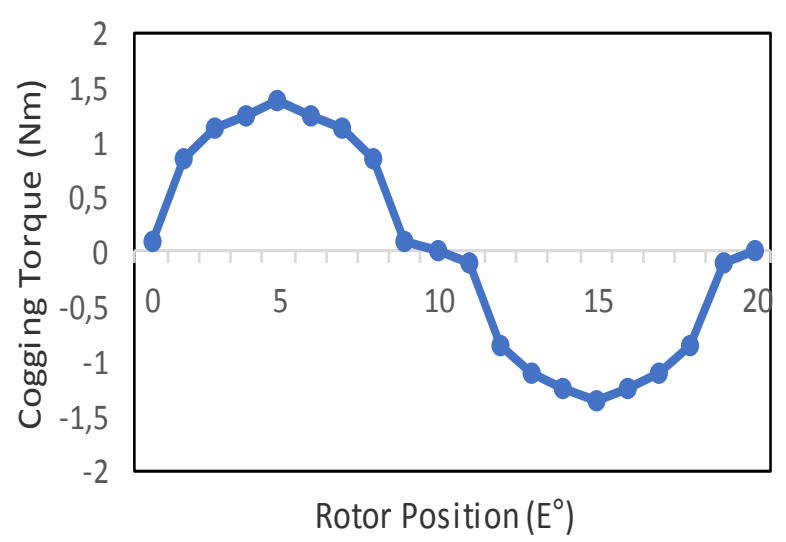

Fig.9. Cogging Torque Graph
The cogging torque of the motor was examined and the maximum cogging torque value was found to be $1.38 \mathrm{Nm}$, and the peak to peak cogging torque value was found as $2.60 \mathrm{Nm}$ according to figure 9 .

\section{F. Noise and Vibration Analysis}

One of the main causes of noise and vibration in electric motors is radial electromagnetic forces on the stator teeth. These electromagnetic forces cause vibration in the stator stack and cause both deformation and noise. Since electromagnetic forces cannot be eliminated theoretically and practically, minimizing these forces is very important for the life of the motor and driven load. Radial electromagnetic force density in the air gap according to the 'Maxwell Stress Tensor' equation

$$
P_{r}(\theta, t)=\frac{b_{F}^{2}\left(\theta_{i} t\right)}{2 \mu_{0}}
$$

it is calculated from the formula [4]. Where $\theta$ is the angular position of the stator, $t$ time, $\mu_{0}$ air gap magnetic permeability, air gap radial flux density $b_{\tilde{\gamma}}^{2}(\theta, t)$.

\section{G. Natural Frequency Analysis}

Natural frequency is the frequency value that depends only on the elasticity and mass of an object and at which the object will vibrate continuously and in high amplitude when it is excited at a certain frequency. In this section, the natural frequencies of the stator geometry for different modes will be examined using Ansys Modal software.

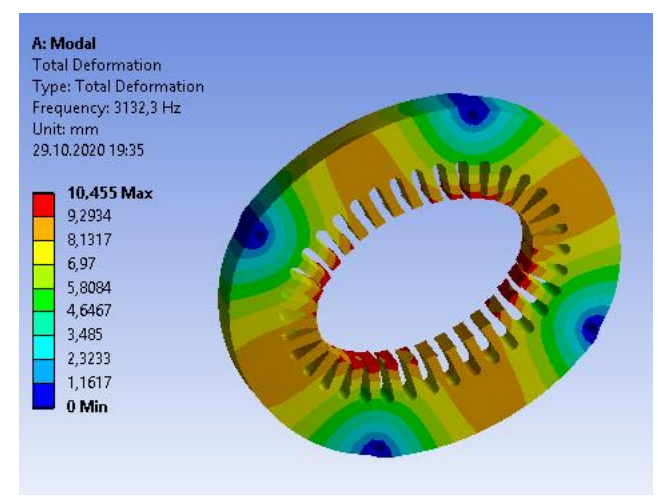

Fig.10. Natural Frequency in First Mode

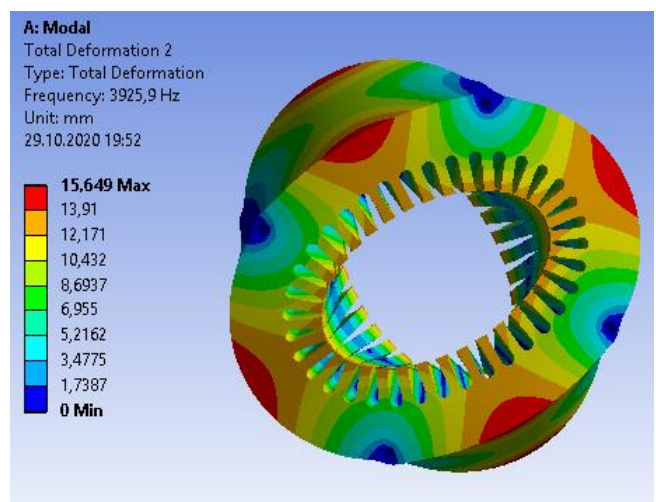

Fig.11. Natural Frequency in Second Mode 


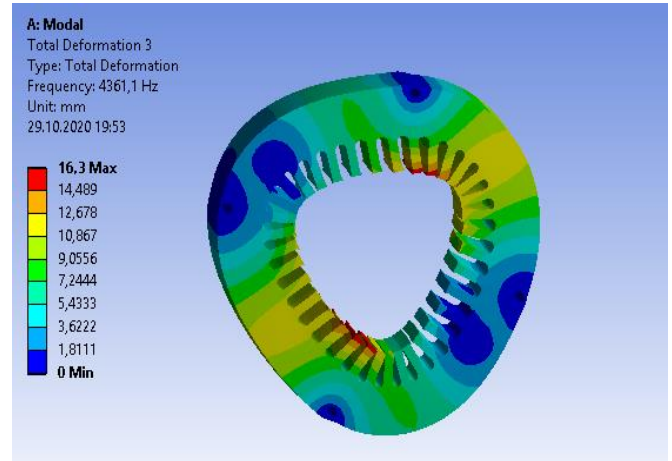

Fig.12. Natural Frequency in Third Mode

The natural frequency analysis results in the first 3 modes were examined. The natural frequencies were obtained from figures $10,11,12$, as $3132.3 \mathrm{~Hz}, 3925.9 \mathrm{~Hz}, 4361.1 \mathrm{~Hz}$, respectively.

\section{H. Harmonic Frequency Analysis}

If the natural frequency of a geometry that makes forced vibrations under a dynamic force and the forced frequency are equal, the material goes into resonance and deformation. In this section, radial electromagnetic forces on the stator teeth are analyzed in Ansys Maxwell software. Then, these forces were transferred to the Ansys Harmonic Response software and the effects of electromagnetic forces on the motor on the stator teeth were analyzed with multiphysics.

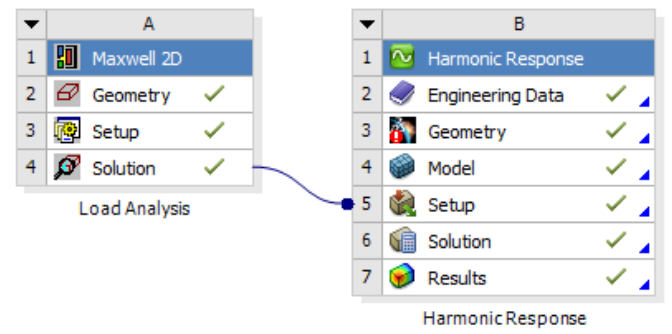

Fig.13. Multiphysics Analysis

TABLE VI

Forces on Stator Teeth

\begin{tabular}{ccccc}
\multicolumn{5}{c}{ Forces on Stator Teeth } \\
\hline \hline $\begin{array}{c}\text { Frequency } \\
{[\mathrm{Hz}]}\end{array}$ & $\begin{array}{c}\mathrm{X} \\
\text { Component } \\
\text { Real [N] }\end{array}$ & $\begin{array}{c}\text { Component } \\
\text { Imag [N] }\end{array}$ & $\begin{array}{c}\text { Component } \\
\text { Real [N] }\end{array}$ & $\begin{array}{c}\text { Component } \\
\text { Imag [N] }\end{array}$ \\
\hline \hline 50 & 0,0040 & 0,0122 & $-0,0018$ & $-0,0037$ \\
100 & $-133,21$ & $-236,5$ & 19,193 & 27,071 \\
150 & $-0,0208$ & 0,0067 & $-0,0054$ & $-0,0131$ \\
200 & $-4,0502$ & $-91,273$ & 8,2426 & 9,7697 \\
300 & 5,0297 & $-26,706$ & 3,0731 & 4,5266 \\
400 & $-10,966$ & $-10,468$ & 2,5416 & $-0,2752$ \\
500 & $-11,229$ & $-14,374$ & 4,1287 & $-0,4252$ \\
600 & $-2,2352$ & $-11,996$ & 3,1109 & 1,296 \\
700 & 0,7360 & $-4,3094$ & 0,9955 & 0,9029 \\
800 & $-0,8957$ & $-1,0045$ & 0,3815 & $-0,4005$ \\
900 & $-0,5218$ & $-0,8281$ & 0,4090 & $-0,5105$ \\
1000 & 0,2447 & $-0,1527$ & 0,0266 & $-0,0697$ \\
\hline \hline
\end{tabular}

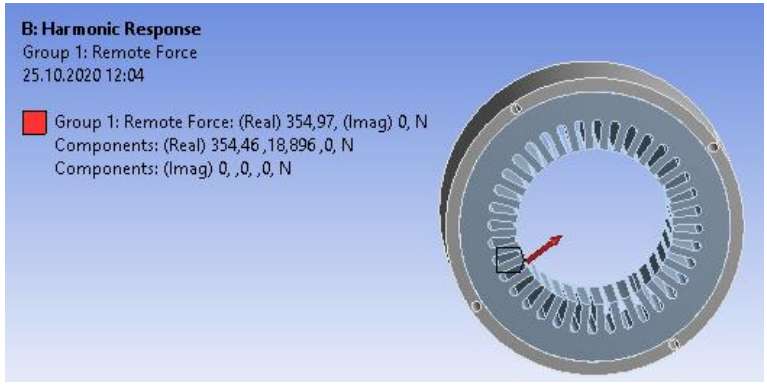

Figure.14. Illustration of the Force on a Stator Tooth

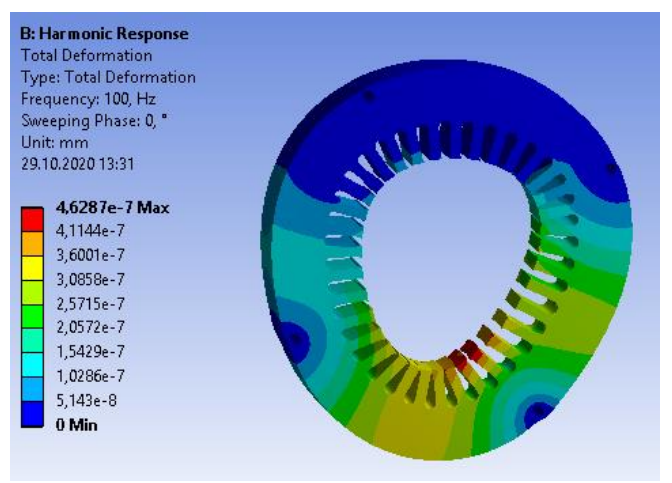

Figure.15. Deformation at $100 \mathrm{~Hz}$

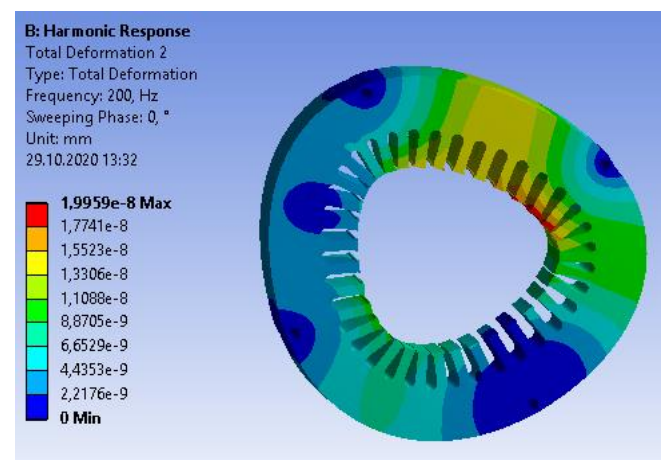

Figure.16. Deformation at $200 \mathrm{~Hz}$

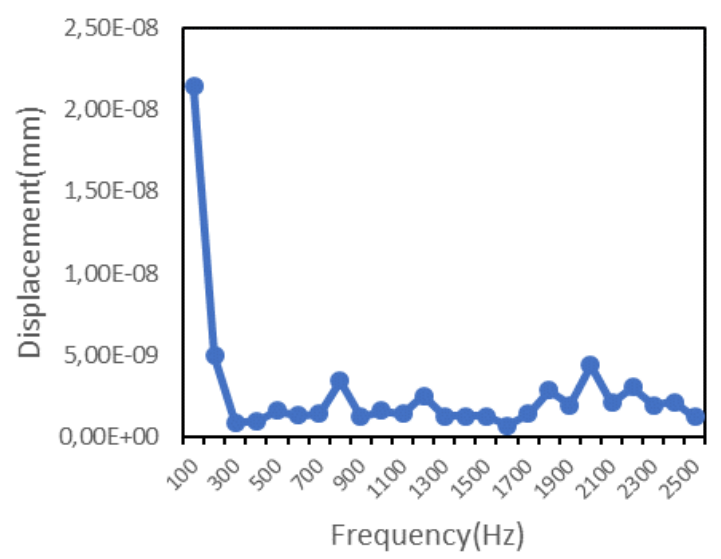

Figure.17. Frequency-Displacement Graph

Here, as seen figure 15, 16 and 17 the displacement values at certain frequencies resulting from the electromagnetic forces as shown table VI and figure 14 are basically the vibration values in the operating state of the motor. These vibrations, which are an energy source, cannot be noticed by the human 
eye and can be measured with measuring devices. At the same time, these vibrations can be felt in the human ear by turning into noise, which is another source of energy, and can be measured with measuring devices.

\section{SECOND DESIGN}

The final design was achieved by optimizing the design in order to make improvements in the cogging torque, torque ripple, efficiency, noise and vibration parameters of the permanent magnet synchronous motor. First of all, it was aimed to reduce the cogging torque and accordingly, torque ripple was also reduced. Magnet geometry has been optimized to reduce the cogging torque as shown figure 18 .

TABLE VII

Second Design Parameters

\begin{tabular}{cc}
\hline \hline Parameter & Value \\
\hline \hline Output Power (kW) & 7.5 \\
Speed (rpm) & 1500 \\
Phase Voltage (V) & 230 \\
Phase Current(rms) (A) & 14.14 \\
Target Efficiency (\%) & 92.6 \\
\hline \hline
\end{tabular}

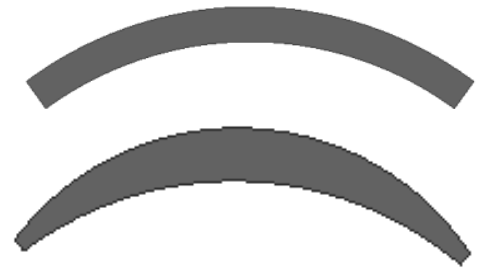

Figure.18. Magnet Geometry Optimization

TABLE VIII Design 1\&2 Motor Dimensions

\begin{tabular}{ccc}
\hline \hline Parameter & Design 1 & Design 2 \\
\hline \hline Stator Outer Diameter(mm) & 218 & 218 \\
Stator Inner Diameter (mm) & 125 & 125 \\
Stator-Rotor Stack Length (mm) & 120 & 100 \\
Slot Number & 36 & 36 \\
Slot Height (mm) & 24 & 25,7 \\
Stator Tooth Width (mm) & 6.6 & 6 \\
Airgap (mm) & 1.5 & 1,5 \\
Max. Magnet Thickness (mm) & 5.5 & 8 \\
Min. Magnet Thickness (mm) & 5.3 & 2,2 \\
Magnet Width (Electrical Degree) & 144 & 155 \\
Magnet Axial Length(mm) & 120 & 100 \\
Number of Turn & 19 & 24 \\
Wire Diameter (mm) & 1.02 & 1 \\
Number of Wire & 4 & 4 \\
Steel Material & $50 J N 400$ & $50 J N 400$ \\
Magnet Material & N45M & N48M \\
\hline \hline
\end{tabular}

It is aimed to obtain the same power in a smaller volume by reducing the stack length of the motor. Accordingly, the need to increase the number of turns has emerged. If the stator slot area were left the same as the first design, we would have to reduce the conductor cross section, and this reduction would increase the winding phase resistance, there would be a significant increase in copper losses. In order to prevent this, the stator slot area has been increased 'without ignoring the flux densities'.

A. Electromagnetic Analysis

In order to examine the effects of changing lamination and magnet geometry on the motor, the electromagnetic analyzes made in the first design were repeated and the results were examined comparatively.

\section{B. Torque Analysis}

The rated torque characteristic of the second design was examined and it was observed that the torque ripple decreased significantly compared to the first design as seen figure 19 and table IX.

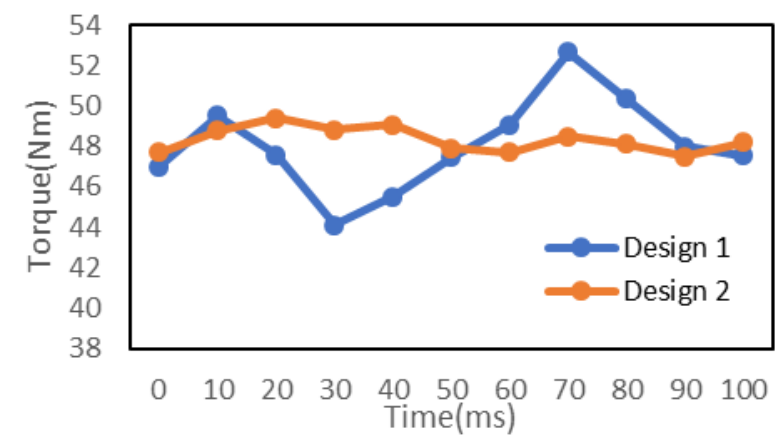

Figure.19. Torque Graphs

Table IX

Torque Values

\begin{tabular}{lccc}
\hline \hline & $\begin{array}{c}\text { Maximum } \\
\text { Torque }(\mathrm{Nm})\end{array}$ & $\begin{array}{c}\text { Minimum } \\
\text { Torque(Nm) }\end{array}$ & $\begin{array}{c}\text { Torque } \\
\text { Ripple }(\%)\end{array}$ \\
\hline \hline Design 1 & 52,65 & 44,12 & 17,64 \\
Design 2 & 49,4 & 47,5 & 3,9 \\
\hline \hline
\end{tabular}

C. Flux Density Analysis

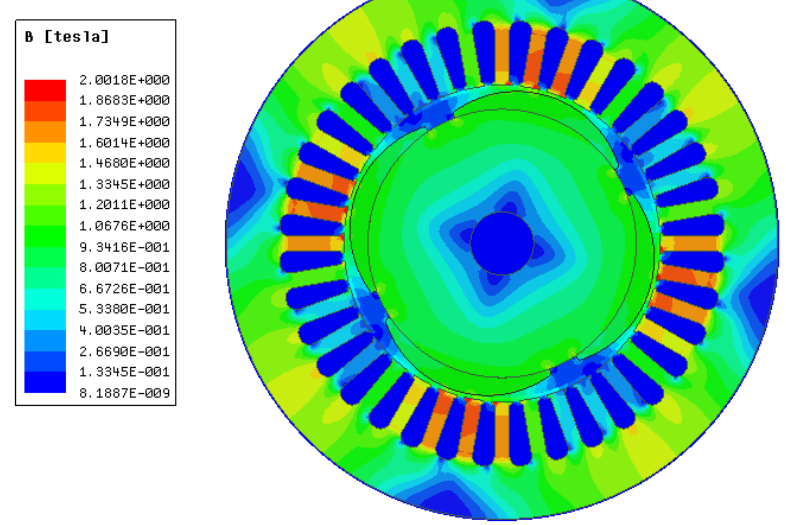

Figure.20. Flux Densities 
Table X

Max. Flux Density Values

\begin{tabular}{ccc}
\hline \multicolumn{3}{c}{ Max. Flux Density Values } \\
\hline \hline Parameter & Design 1(T) & Design 2(T) \\
Stator Yoke & 1,6 & 1,5 \\
Stator Teeth & 1,73 & 1,77 \\
Airgap & 1,16 & 1,13 \\
Rotor Yoke & 1,27 & 1,2 \\
\hline \hline
\end{tabular}

It has been observed that the flux densities in design 2 do not lead the $50 \mathrm{JN} 400$ electrical steel to the saturation point, as seen figure 20 and table $X$.

\section{Determination of Losses}

In the second design, the volume of the motor was reduced, the stator-rotor axial length was decreased, the magnet volume was increased, and the iron losses of the motor, which could achieve $7.5 \mathrm{~kW}$ output power with less phase current, were significantly reduced as seen figure 21 . With the reduction of iron losses, an improvement has been made in the efficiency parameter as seen table XI.

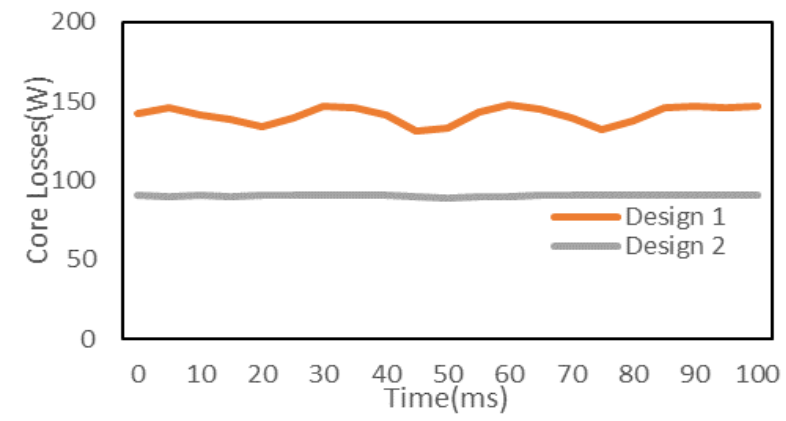

Figure.21. Core Losses Graph

Table XI

Comparative Result of Losses

\begin{tabular}{lcc}
\hline \hline Losses & Design 1 & Design 2 \\
\hline \hline Copper Losses (W) & 325,7 & 340 \\
Core Losses (W) & 140,75 & 89,67 \\
Magnet Losses (W) & 3,4 & 1,19 \\
Friction and Windage Losses(W) & 28 & 28 \\
Additional Losses (W) & 51 & 51 \\
\hline \hline Total Losses(W) & 548,85 & 509,86 \\
\hline \hline Efficiency (\%) & 93,18 & 93,63 \\
\hline \hline
\end{tabular}

\section{E. Cogging Torque Analysis}

After optimizing the magnet geometry in the first design, it is observed that the cogging torque obtained in the second design is significantly reduced as seen figure 22 and table XII.

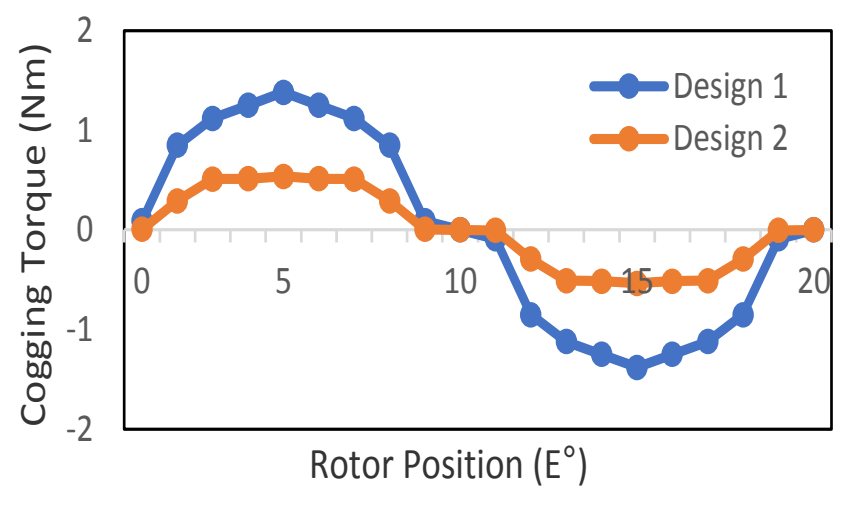

Figure.22. Cogging Torque Graph Design 1\&2

Table XII

Cogging Torque Values

\begin{tabular}{lcc}
\hline \hline & $\begin{array}{c}\text { Max. Cogging } \\
\text { Torque(Nm) }\end{array}$ & $\begin{array}{c}\text { Peak to Peak Cogging } \\
\text { Torque }(\mathrm{Nm})\end{array}$ \\
\hline \hline Design 1 & 1,38 & 2,6 \\
Design 2 & 0,537 & 1,07 \\
\hline \hline
\end{tabular}

F. Noise and Vibration Analysis

First, natural frequency analyzes of the stator stack fixed at 4 points were performed.



Fig.23. Natural Frequency in First Mode

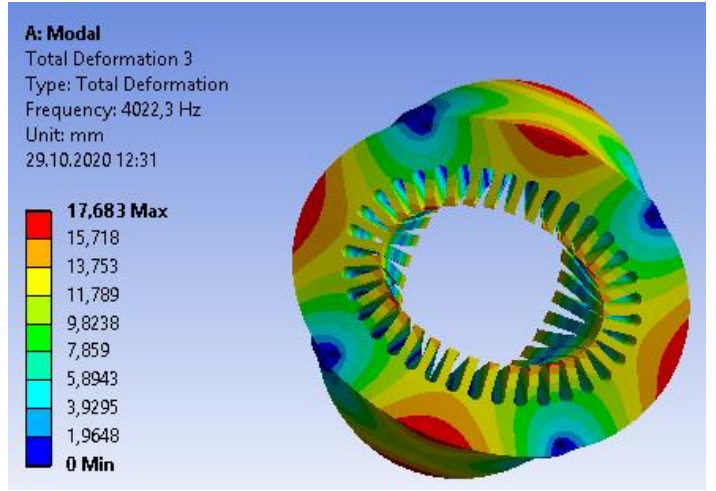

Fig.24. Natural Frequency in Second Mode 


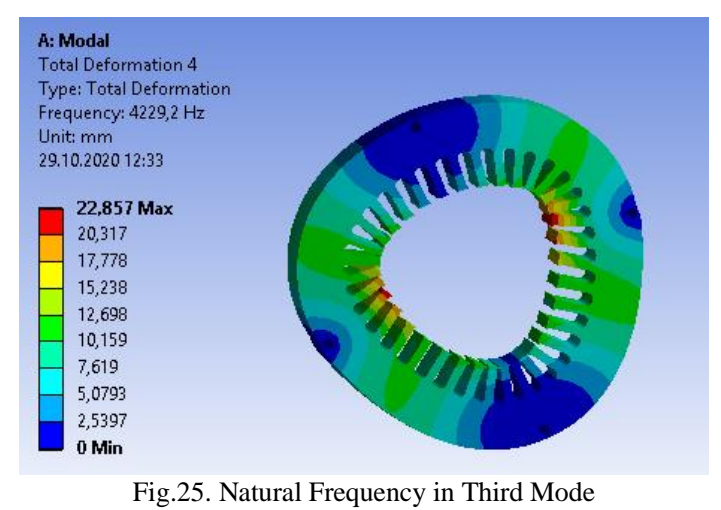

The natural frequency analysis results in the first 3 modes were examined. The natural frequencies were obtained as seen figure 23,24 and 25 as $3181 \mathrm{~Hz}, 4022.3 \mathrm{~Hz}, 4229.2 \mathrm{~Hz}$ respectively.

\section{G. Harmonic Frequency Analysis}

In this section, firstly, electromagnetic forces on stator teeth are analyzed. These forces were transferred to the Ansys Harmonic Response software and multiphysics analyzes were performed.

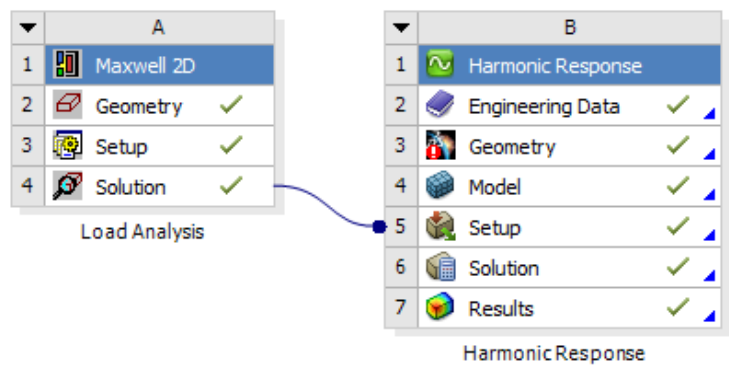

Fig.26. Multiphysics Analysis

Table XIII

Forces on Stator Teeth

\begin{tabular}{|c|c|c|c|c|}
\hline $\begin{array}{c}\text { Frequency } \\
{[\mathrm{Hz}]}\end{array}$ & $\begin{array}{c}\mathrm{X} \\
\text { Component } \\
\text { Real }[\mathrm{N}] \\
\end{array}$ & $\begin{array}{c}\mathrm{X} \\
\text { Component } \\
\text { Imag [N] } \\
\end{array}$ & $\begin{array}{c}\mathrm{Y} \\
\text { Component } \\
\text { Real }[\mathrm{N}] \\
\end{array}$ & $\begin{array}{c}\mathrm{Y} \\
\text { Component } \\
\text { Imag [N] } \\
\end{array}$ \\
\hline 50 & 0,0014 & $-0,0265$ & $-0,0023$ & $-0,0012$ \\
\hline 100 & 211,7 & 73,7020 & 13,547 & 20,6710 \\
\hline 150 & $-0,0052$ & 0,0103 & $-0,0011$ & 0,0024 \\
\hline 200 & $-23,9610$ & $-2,4352$ & 2,9854 & $-5,7988$ \\
\hline 250 & $-0,0016$ & 0,0036 & 0,0013 & 0,0022 \\
\hline 300 & $-3,2879$ & $-7,6070$ & $-1,1511$ & 0,4653 \\
\hline 400 & $-0,2876$ & $-1,3666$ & 0,2533 & $-0,3375$ \\
\hline 500 & $-1,1707$ & 0,4757 & 0,1951 & 0,3020 \\
\hline 600 & $-0,1889$ & $-0,5597$ & 0,2464 & $-0,1932$ \\
\hline 700 & 0,3106 & $-0,1428$ & 0,1886 & $-0,0390$ \\
\hline 800 & $-0,2089$ & $-0,0673$ & $-0,0786$ & $-0,0262$ \\
\hline 900 & $-0,2182$ & $-0,0506$ & 0,0404 & $-0,0931$ \\
\hline 1000 & 0,1428 & 0,1800 & $-0,2347$ & $-0,0542$ \\
\hline
\end{tabular}

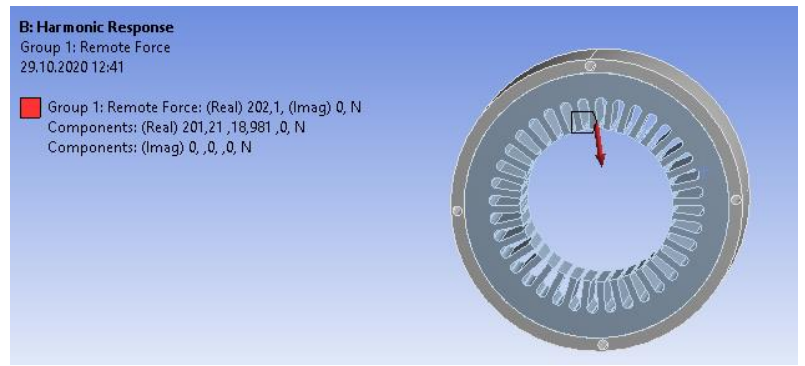

Figure.27. Illustration of the Force on a Stator Tooth

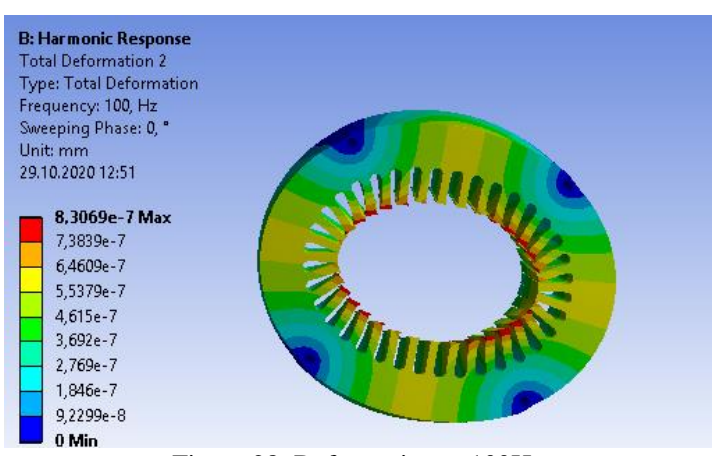

Figure.28. Deformation at $100 \mathrm{~Hz}$

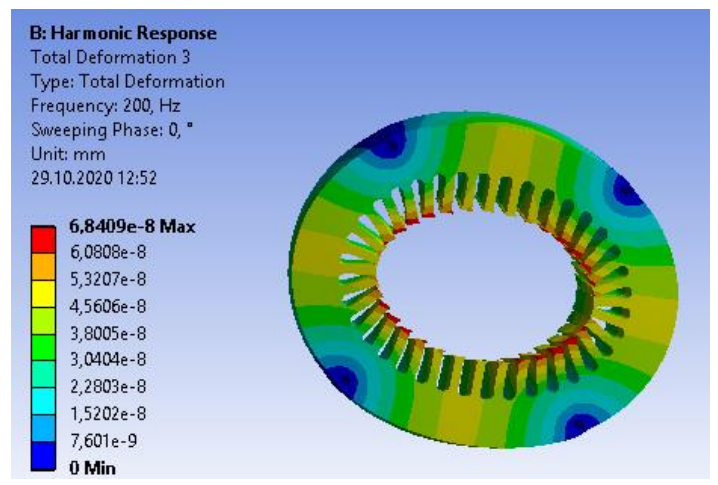

Figure.29. Deformation at $200 \mathrm{~Hz}$

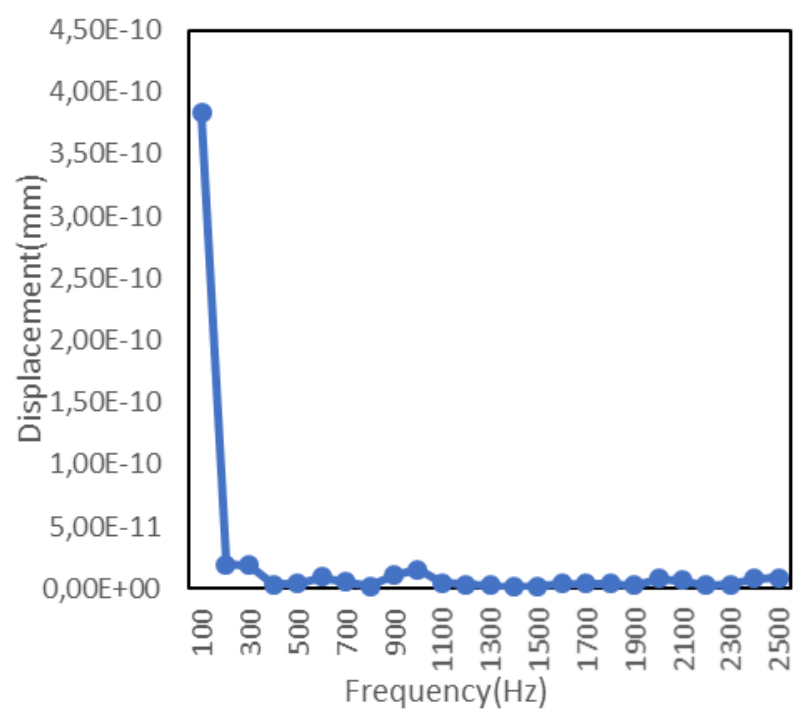

Figure.30. Frequency-Displacement Graph

Electromagnetic forces on stator teeth was shown at figure 27 and table XIII. The displacement, causes from electromagnetic 
forces, values of the motor at certain frequencies as shown figure 28, 29 and 30. Under radial electromagnetic forces the displacement values design $1 \& 2$ were compared at table XIV.

Table XIV

Displacement Values for Design 1\&2

\begin{tabular}{ccc}
\hline \hline & \multicolumn{2}{c}{ Displacement(mm) } \\
\hline \hline Frequency(Hz) & Design 1 & Design 2 \\
\hline \hline 100 & $2.15 \times 10^{-8}$ & $3.83 \times 10^{-10}$ \\
200 & $4.97 \times 10^{-9}$ & $1.96 \times 10^{-11}$ \\
300 & $9.23 \times 10^{-10}$ & $1.92 \times 10^{-11}$ \\
400 & $9.82 \times 10^{-10}$ & $3.54 \times 10^{-12}$ \\
500 & $1.63 \times 10^{-9}$ & $3.99 \times 10^{-12}$ \\
600 & $1.35 \times 10^{-9}$ & $9.13 \times 10^{-12}$ \\
700 & $1.46 \times 10^{-9}$ & $5.29 \times 10^{-12}$ \\
800 & $3.45 \times 10^{-9}$ & $1.88 \times 10^{-12}$ \\
900 & $1.25 \times 10^{-9}$ & $1.10 \times 10^{-11}$ \\
1000 & $1.66 \times 10^{-9}$ & $1.54 \times 10^{-11}$ \\
\hline \hline
\end{tabular}

The second design with lower cogging torque and torque ripple were obtained, the displacement values of the motor at the same frequency compared to the first design. Improvement work on the cogging torque and torque ripple also led to the reduction of radial electromagnetic forces on the stator teeth and the displacement of the motor under these forces was reduced. The fact that the displacement values are reduced also means that the noise and vibration values of the motor will be lower than the first design.

\section{CONCLUSION}

Within the scope of this study, the design and optimization of a 3-phase permanent magnet synchronous motor with $7.5 \mathrm{~kW}$ output power and 1500rpm rotation speed for industrial applications was carried out. After the first design, finite element analysis was made and the performance results of the motor were examined. The design was optimized and a second design was made in order to improve the cogging torque, efficiency, noise and vibration parameters. As in the first design, both electromagnetic and structural analyzes of the obtained second design were performed using the finite element method, the results were analyzed comparatively. With this final design, the targeted improvements were made in the determined parameters and the motor design with smaller volume, higher efficiency, lower cogging torque, torque ripple, noise and vibration compared to the motor that was originally designed was realized.

\section{ACKNOWLEDGMENT}

The authors would like to thank Gamak Makina Sanayi A.Ş for their support in this study.

\section{REFERENCES}

[1] D. Hanselman, "Brushless Permanent Magnet Motor Design." Second Edition, 2006.

[2] J. F. Gieras, "Permanent Magnet Motor Technology." Third Edition, 2010.

[3] Y. Xie, Y. Xia, Z. Li, F. Li, "Analysis of modal and vibration reduction of an interior permanent magnet synchronous motor." Energies 12(18): 3427, September 2019.

[4] Y. Wang, H. Gao, H. Wang, W. Ma, "NVH optimization analysis of permanent magnet motor by rotor slotting", Vehicles 2(2): 287-303, May 2020.

[5] S. Sathyan, U. Aydin, A.Belachen, "Acoustic noise computation of electrical motors using boundary element method", Energies 13(1): 245, January 2020.

[6] Helder Sá Alves da Silva, 'Design for Manufacture of Brushless Permanent Magnet Synchronous Servomotors", 2014.

[7] M. Chabchoub, I. B. Salah, G. Krebs, R. Neji, C. Marchand, "PMSM cogging torque reduction: Comparison between different shapes of magnet ", First International Conference on Renewable Energies and Vehicular Technology, 2012.

[8] M. Rizwan, M. Arun Noyal Doss, "Reduction of cogging torque in pmbldc motor with reduced stator tooth width and bifurcated surface area using finite element analysis", 2011

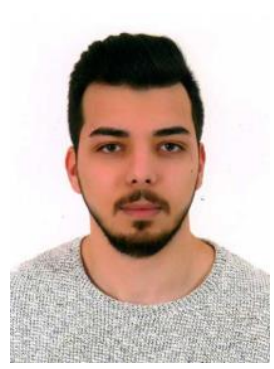

\section{BIOGRAPHIES}

ATAKAN ŞAHIN was born in 1995. He received the B.S. degree in electrical engineering from the Yildiz Technical University, İstanbul, in 2018. He has started M.Sc. at 2019 at Yildız Technical University electrical engineering department, electrical machines and power electronics program.

He has been working at Gamak Makina Sanayi A.Ş R\&D department as electrical design engineer since February 2019. His research and professional interests include: electrical motors design \& optimization, advanced electromagnetic analysis, noise and vibration analysis, ac motor drives, electrical motors performance test systems.



for electrical machines.
YASEMIN ÖNER received the B.Eng., M.Sc., and Ph.D. degrees in electrical engineering from Yildiz Technical University, Istanbul, Turkey, in 2007, 2009, and 2013, respectively. She is currently Associate Prof. Dr. in Yildiz Technical University. Her research interests include analytical solutions 